Syntax Literate : Jurnal Ilmiah Indonesia p-ISSN: 2541-0849

e-ISSN : 2548-1398

Vol. 5, No. 2 Februari 2020

\title{
PENGARUH EFEKTIVITAS SENAM DISMENORE TERHADAP PENURUNAN INTENSITAS NYERI DISMENORE PADA REMAJA PUTRI DI SMK YPIB MAJALENGKA KABUPATEN MAJALENGKA TAHUN 2019
}

\section{Ayu Idaningsih dan Fitri Oktarini}

Sekolah Tinggi Ilmu Kesehatan (STIKes) YPIB Majalengka

Email: ayu.idaningsih@yahoo.com dan fitrioktarini2810@gmail.com

\section{Abstract}

Dysmenorrhea (dysmenorrhea) is pain that is felt during menstruation caused by uterine muscles that overcome spasms. One effort to reduce the intensity of dysmenorrhea can be done with dysmenorrhea gymnastics. This research aims to know the effectiveness effect of dysmenorrhea gymnastic on decreasing the intensity of dysmenorrhea pain in young girls in the Vocational high school YPIB of Majalengka 2019. The kind of research that is experimental research with pretestposttest Control Group design. The sample from this research amount to 30 girl student class X and XI in the Vocational high school YPIB of Majalengka that is 15 experiment groups and 15 control groups. That research is done on 15 April-15 May 2019. Data analysis uses univariate analysis with frequency distribution, normality test and bivariate analysis with paired t-test. The results of the research indicated that before dysmenorrhea gymnastic more than half (66,7\%) young girl have experienced pain intensity when doing dysmenorrhea gymnastic and after do it too. Effectiveness dysmenorrhea gymnastic decrease pain intensity on young girl in vocational high school YPIB of Majalengka 2019. The level of decreasing pain intensity before and after doing dysmenorrhea gymnastic amount of 1,8. For parties of vocational high school YPIB of Majalengka need to upgrade information about reproduction health on young girl especially about dysmenorrhea through some activities such as counseling cooperate with public health office or public health center, discussion about menstruation, using madding to share insight for student about menstrual discussion and treatment and optimize the role of the School Health Unit (UKS) in handle students who feel menstrual pain.

Keywords : Dismenore, Intensitas Nyeri, Senam Dismenore

\begin{abstract}
Abstrak
Dismenore (dysmenorrhea) adalah rasa nyeri yang dialami ketika menstruasi yang disebabkan oleh otot uterus yang mengalami kejang. Salah satu upaya untuk menurunkan intensitas dismenore dapat dilakukan dengan senam dismenore. Penelitian ini bertujuan untuk mengetahui pengaruh efektivitas senam dismenore terhadap penurunan intensitas nyeri dismenore pada remaja putri di SMK YPIB Majalengka Kabupaten Majalengka Tahun 2019 Jenis penelitiannya yaitu penelitian eksperimen dengan desain Pretest-Postest Control Group Design. Sampel dalam penelitian ini sebanyak 30 orang siswi kelas X dan XI di SMK YPIB Majalengka yaitu 15 kelompok eksperimen dan 15 kelompok kontrol. Penelitiannya dilakukan
\end{abstract}


pada tanggal 15 April-15 Mei 2019. Analisis datanya menggunakan analisis univariat dengan distribusi frekuensi, uji normalitas dan analisis bivariat dengan uji t berpasangan. Hasil penelitian menyatakan bahwa sebelum senam dismenore lebih dari setengah $(66,7 \%)$ remaja putri mengalami intensitas nyerinya sedang dan sesudah senam dismenore lebih dari setengah $(77,3 \%)$ remaja putri mengalami intensitas nyerinya ringan saat dismenore. Senam dismenore efektivitas terhadap penurunan intensitas nyeri dismenore pada remaja putri di SMK YPIB Majalengka Kabupaten Majalengka Tahun 2019. Besarnya penurunan intensitas nyeri sebelum dan sesudah senam dismenore sebesar 1,8. Bagi pihak SMK YPIB Majalengka perlu meningkatkan informasi tentang kesehatan reproduksi pada remaja terutama tentang dismenore melalui beberapa kegiatan seperti penyuluhan bekerja sama dengan dinas kesehatan atau puskesmas terdekat, diskusi remaja seputar menstruasi, memanfaatkan sarana informasi seperti mading untuk menyebarkan wawasan kepada siswa tentang pencegahan dan penanganan menstruasi, serta mengoptimalkan peran Unit Kesehatan Sekolah (UKS) dalam menangani siswi yang mengalami nyeri menstruasi

Kata kunci: Dismenore, Intensitas Nyeri, Senam Dismenore

\section{Pendahuluan}

Masa remaja adalah masa peralihan manusia dari anak-anak menuju dewasa, ditandai adanya percepatan perkembangan fisik, emosi, mental dan sosial (Laila, 2015). Perubahan-perubahan fisik yang dialami oleh remaja yang memiliki pengaruh besar terhadap perkembangan jiwa remaja yaitu pertumbuhan tubuh seperti badan semakin tinggi dan panjang. Diikuti dengan mulai berfungsinya alat-alat reproduksi (ditandai dengan menstruasi pada wanita) menstruasi ini sebagai tanda seksual sekunder pada remaja dan ada beberapa remaja yang mengalami gangguan pada saat menstruasi yaitu mengalami nyeri pada saat menstruasiatau dismenore (Marmi., 2014).

Menurut data World Health Organization atau WHO (Savitri, 2015), didapatkan kejadian dismenore pada wanita sebanyak 1.769 .425 jiwa (90\%) dengan 10-15\% mengalami dismenore berat. Studi epidemiologi di Mesir melaporkan kejadian dismenore pada $75 \%$ remaja perempuan pubertas dengan jumlah ketidakhadiran di sekolah sebesar 20,3\% yang dihubungkan dengan beratnya gejala (Laila, 2015). Menurut (Dahlan, 2017) hampir 90\% wanita di Amerika Serikat mengalami dismenore, dan $10-15 \%$ diantaranya mengalami dismenore berat, akibatnya penderita tidak mampu melakukan kegiatan apapun. Sedangkan $80 \%$ remaja usia 19-21 tahun mengalami dismenore ini hasil dari penelitian dari Swedia, $15 \%$ membatasi aktifitas harian mereka ketika menstruasi dan membutuhkan obat-obatan untuk mengurangi dismenore, 8-10\% tidak mengikuti atau masuk sekolah dan hampir $40 \%$ finansial dan kualitas hidup perempuan berdampak tidak baik (Oktasari, 2015).

Begitu pula angka kejadian dismenore di Indonesia cukup tinggi yaitu sebesar 54,89\% dismenore primer dan 9,36\% dismenore sekunder (Dahlan, 2017). Adapun angka kejadian dismenore di Jawa Barat tahun 2015 yaitu sebesar 72,89\% dismenore primer dan 27,11\% dismenore sekunder (Andriyani, 2016). 
Nyeri merupakan perasaan yang mengganggu kenyamanan akibat suatu hal, keadaan ini hanya dapat dijelaskan oleh penderita nyeri tersebut terkait sebab dan/atau tempat dimana rasa nyeri itu timbul. Secara umum rasa nyeri merupakan perasaan tidak nyaman yang erat kaitannya dengan gangguan tubuh dan factor lain. Salah satu skala nyeri diantaranya menggunkan Numeric Rating Scale (NRS) (Subandi, 2017).

Dismenore (dysmenorrhea) adalah nyeri yang dirasakan selama menstruasi yang disebabkan oleh otot uterus yang mengalami kejang (Price, 2016). Dismenore bisa terjadi akibat prostaglanding yang dikandung oleh endometrium berada pada jumlah yang tingggi, hal ini disebabkan oleh progesterone selama fase luteal pada siklus haid, prostaglandin mencapai tingkat maksimum pada awal haid, sehingga menyebabkan kontraksi miometrium yang kuat dan mampu menyempitkan pembuluh darah, menyebabkan iskemia, disintegrasi endometrium, perdarahan dan nyeri (Manuaba, 2015). Dismenore dapat menghambat aktivitas remaja yang berdampak pada penurunan prestasi remaja di sekolah karena ketidakhadirannya dalam proses pembelajaran. Studi yang lain melaporkan bahwa dismenore menyebabkan 14\% remaja sering tidak masuk sekolah (Perry dan Potter, 2015).

Tingkat nyeri dibagi atas skala kategorik (tidak nyeri, sakit ringan, sakit sedang dan sakit berat). Nyeri merupakan keadaan dimana seseorang membuat alasan untuk dirinya mencari bantuan perawatan kesehatan yang menjadi penyebab dari pengalaman sensori dan emosional yang tidak menyenangkan. Nyeri terjadi bersama banyak proses penyakit atau bersamaan dengan beberapa pemeriksaan diagnostik atau pengobatan (Perry dan Potter, 2015).

Senam dismenore merupakan salah satu bentuk relaksasi yang sangat dianjurkan. Tujuan dilakukannya senam dismenore adalah mengurangi dismenore yang dialami oleh beberapa wanita tiap bulannya (Suparto, 2015). Hal ini disebabkan saat melakukan olahraga atau senam, tubuh akan menghasilkan hormon endorphin. Endorphin dihasilkan oleh otak dan susunan saraf tulang belakang. Hormon ini berperan sebagai obat penenang alami yang diproduksi oleh otak sehingga menimbulkan rasa nyaman (Haruyama, 2014). Pada seorang atlet yang teratur berolahraga memiliki tingkat prevalensi kejadian dismenore lebih rendah dibandingkan dengan wanita yang mengalami obesitas, dan pada wanita yang memiliki siklus menstruasi yang tidak teratur (Laila, 2015).

Hasil penelitian di Desa Sidoharjo Kecamatan Pati menunjukkan bahwa ada pengaruh senam dismenore terhadap penurunan dismenore pada remaja putri dengan nilai $\rho$ sebesar 0,041. Hasil penelitian (Sormin, 2014) menunjukkan bahwa senam dismenore efektif dalam mengurangi dismenore pada remaja putri di SMP Negeri 2 Siantan dengan nilai $\rho$ sebesar 0,000 .

Berdasarkan data dari SMK YPIB Majalengka tahun ajaran 2018/2019 diketahui jumlah seluruhnya sebanyak 399 orang, yang terdiri dari tiga jurusan, yaitu Farmasi sebanyak 199 siswa, Keperawatan sebanyak 145 siswa dan Analis Kimia sebanyak 55 orang. Untuk siswa kelas X hanya ada dua jurusan yaitu Farmasi dan Keperawatan. Jumlah kelassiswa X sebanyak 4 kelas dengan jumlah siswa sebanyak 106 orang yang 
terdiri dari 6 laki-laki dan 100 perempuan, kelas XI sebanyak 5 kelas dengan jumlah siswa sebanyak 156 orang yang terdiri dari 16 laki-laki dan 140 perempuan dan kelasXII sebanyak 5 kelas dengan jumlah siswa sebanyak 137 orang yang terdiri dari 20 laki-laki dan 117 perempuan. Penelitian ini dilakukan pada siswa kelas X dan XI, dikarenakan siswa kelas XII pada bulan Maret-April 2019 akan melaksanakan ujian nasional sehingga tidak dapat diikutsertakan pada penelitian ini.

Berdasarkan studi pendahuluan yang dilakukan oleh peneliti pada tanggal 21 Januari 2019 terhadap 30 remaja puteri di SMK YPIB Majalengka, diketahui sebanyak 15 orang $(50 \%)$ mengalami dismenore.Secara keseluruhan remaja belum tahu tentang senam dismenore dan dari 15 orang yang dismenore sebanyak 8 orang mengatakan ketika dismenore mereka minum obat untuk mengatasi nyeri dan 7 orang lainnya tidak melakukan apa-apa atau hanya istirahat saja.

\section{Metode Penelitian}

Jenis penelitian yang dipakai pada penelitian ini adalah penelitian eksperimendengan desain penelitian Pretest-Postest Control Group Design.Jumlah sampel yang digunakan sebanyak 30 orang yang sedang mengalami dismenore. Responden tersebut dibagi menjadi dua kelompok yaitu kelompok eksperimen yang dismenore dan diberi perlakuan dan kelompok kontrol yang dismenore tidak diberi perlakuan masing-masing berjumlah 15 orang. Penelitian ini telah dilakukan di SMK YPIB Majalengka Kabupaten Majalengka pada tanggal 15 April-15 Mei 2019. Instrumen yang digunakan dalam penelitian ini adalahkuesioner lembar observasi. Kuesioner pada penelitian ini yaitu tentang pengukuran skala nyeri model Visual Analog Scale (VAS).

\section{Hasil Penelitian dan Pembahasan}

\section{Hasil}

a. Analisis Univariat

1) Gambaran Intensitas Nyeri Sebelum dan Sesudah Senam Dismenore

Tabel 1

Distribusi Frekuensi Intensitas Nyeri Sebelum dan Sesudah Senam

Dismenore pada Remaja Putri pada Kelompok Eksperimen di SMK YPIB Majalengka Kabupaten Majalengka Tahun 2019

\begin{tabular}{clcccc}
\hline No & $\begin{array}{c}\text { Intensitas Nyeri } \\
\text { Pada Kelompok } \\
\text { Eksperimen }\end{array}$ & \multicolumn{2}{c}{$\begin{array}{c}\text { Pengukuran yang } \\
\text { ke-1 } \\
\text { (Pretest) }\end{array}$} & $\begin{array}{c}\text { Pengukuran yang } \\
\text { ke-2 } \\
\text { (Postest) }\end{array}$ \\
\cline { 3 - 6 } & & $\mathbf{F}$ & $\mathbf{\%}$ & $\mathbf{F}$ & \% \\
\hline 1 & Sangat berat & 0 & 0 & 0 & 0 \\
2 & Berat & 2 & 13.3 & 0 & 0 \\
3 & Sedang & 10 & 66.7 & 4 & 26.7 \\
4 & Ringan & 3 & 20.0 & 11 & 73.3 \\
5 & Tidak nyeri & 0 & 0 & 0 & 0 \\
\hline & \multicolumn{1}{c}{ Jumlah } & $\mathbf{1 5}$ & $\mathbf{1 0 0}$ & $\mathbf{1 5}$ & $\mathbf{1 0 0 . 0}$ \\
\hline
\end{tabular}


Berdasarkan table 1 diketahui bahwa dari 15 siswi sebelum senam dismenore yang intensitas nyerinya sangat berat tidak ada $(0 \%)$, yang intensitas nyerinya berat sebanyak 2 orang (13,3\%), yang intensitas nyerinya sedang sebanyak 10 orang $(66,7 \%)$, yang intensitas nyerinya ringan sebanyak 3 orang $(20,0 \%)$ dan yang tidak nyeri tidak ada (0\%). Hal tersebut menunjukkan bahwa sebelum senam dismenore lebih dari setengah $(66,7 \%)$ remaja putri pada kelompok eksperimenmengalami intensitas nyerinya sedang saat dismenore. Adapun sesudah senam dismenore dari 15 siswi yang intensitas nyerinya sangat berat tidak ada $(0 \%)$, yang intensitas nyerinya berat tidak ada $(0 \%)$ yang intensitas nyerinya sedang sebanyak 4 orang $(26,7 \%)$, yang intensitas nyerinya ringan sebanyak 11 orang $(73,3 \%)$ dan yang tidak nyeri tidak ada $(0 \%)$. Hal tersebut menunjukkan bahwa sesudah senam dismenore lebih dari setengah $(77,3 \%)$ remaja putri pada kelompok eksperimen mengalami intensitas nyerinya ringan saat dismenore.

Tabel 2

Distribusi Frekuensi Intensitas Nyeri Sebelum dan Sesudah Senam Dismenore pada Remaja Putri pada Kelompok Kontrol di SMK YPIB Majalengka Kabupaten Majalengka Tahun 2019

\begin{tabular}{|c|c|c|c|c|c|}
\hline \multirow[t]{2}{*}{ No } & \multirow{2}{*}{$\begin{array}{c}\text { Intensitas Nyeri } \\
\text { Pada Kelompok } \\
\text { Kontrol }\end{array}$} & \multicolumn{2}{|c|}{$\begin{array}{c}\text { Pengukuran yang } \\
\text { ke-1 } \\
\text { (Pretest) }\end{array}$} & \multicolumn{2}{|c|}{$\begin{array}{c}\text { Pengukuran yang } \\
\text { ke-2 } \\
\text { (Postest) }\end{array}$} \\
\hline & & $\mathbf{F}$ & $\%$ & $\mathbf{F}$ & $\%$ \\
\hline 1 & Sangat berat & 0 & 0 & 0 & 0 \\
\hline 2 & Berat & 1 & 6.7 & 1 & 6.7 \\
\hline 3 & Sedang & 12 & 80.0 & 11 & 73.3 \\
\hline 4 & Ringan & 2 & 13.3 & 3 & 20.0 \\
\hline 5 & Tidak nyeri & 0 & 0 & 0 & 0 \\
\hline & Jumlah & 15 & 100 & 15 & 100.0 \\
\hline
\end{tabular}

Berdasarkan tabel 2 diketahui bahwa dari 15 siswi kelompok kontrol pada pengukuran yang ke-1 (pretest) yang intensitas nyerinya sangat berat tidak ada $(0 \%)$, yang intensitas nyerinya berat sebanyak 1 orang $(6,7 \%)$, yang intensitas nyerinya sedang sebanyak 12 orang $(80,0 \%)$, yang intensitas nyerinya ringan sebanyak 2 orang $(13,3 \%)$ dan yang tidak nyeri tidak ada $(0 \%)$. Hal tersebut menunjukkan bahwa pada kelompok kontrol lebih dari setengah $(80,0 \%)$ remaja putrimengalami intensitas nyerinya sedang saat dismenore pada saat pengukuran yang ke-1. Adapun pada pengukuran yang ke-2 dari 15 siswi kelompok kontrol yang intensitas nyerinya sangat berat tidak ada $(0 \%)$, yang intensitas nyerinya berat sebanyak 1 orang $(6,7 \%)$, yang intensitas nyerinya sedang sebanyak 11 orang $(73,3 \%)$, yang intensitas nyerinya ringan sebanyak 3 orang $(20,0 \%)$ dan yang tidak nyeri tidak ada $(0 \%)$. Hal tersebut menunjukkan bahwa pada kelompok kontrol lebih dari 
setengah $(73,3 \%)$ remaja putrimengalami intensitas nyerinya sedang saat dismenore pada saat pengukuran yang ke-2.

b. Analisis Bivariat

1) Efektivitas Senam Dismenore Terhadap Penurunan Intensitas Nyeri Dismenore

Sebelum dilakukan uji t, sebagai salah satu syaratnya data diuji normalitas terlebih dahulu. Uji normalitas pada penelitian ini menggunakan uji Shapiro Wilk karena memiliki sampel kurang dari 50 subjek atau responden. Adapun hasil uji normalitas dengan Shapiro Wilksebagai berikut:

Tabel 3

Distribusi Uji Normalitas Efektivitas Senam Dismenore Terhadap Penurunan Intensitas Nyeri Dismenore pada Remaja Putri di SMK YPIB Majalengka Kabupaten Majalengka Tahun 2019

\begin{tabular}{lccc}
\hline \multirow{2}{*}{ Variabel } & \multicolumn{3}{c}{ Saphiro Wilk } \\
\cline { 2 - 4 } & Statistic & df & p value \\
\hline Eksperimen & & & \\
Nyeri sebelum (pretest) & .936 & 15 & .333 \\
Nyeri sesudah (postest) & .807 & 15 & .058 \\
Kontrol & & & \\
Nyeri sebelum (pretest) & .924 & 15 & .224 \\
Nyeri sesudah (postest) & .924 & 15 & .218 \\
\hline
\end{tabular}

Berdasarkan tabel 3 diketahui bahwadidapatkan hasil uji normalitas dengan uji Shapiro Wilkdiperoleh $\rho_{\text {value }}$ untuk data pada kelompok eksperimen nyeri sebelum (pretest) adalah 0,333, nyeri sesudah (postest) adalah 0,058, sementara untuk data pada kelompok kontrol nyeri sebelum (pretest) adalah 0,224, nyeri sesudah (postest) adalah 0,218. Hal ini menunjukkan bahwa $\rho_{\text {value }}$ dari keempat data tersebut $>0,05$ dengan demikian data berdistribusi normal. Karena data hasil penelitian berasal dari distribusi yang normal maka analisisnya dapat dilanjutkan dengan uji t berpasangan ataupaired sample t-test.

Tabel 4

Efektivitas Senam Dismenore Terhadap Penurunan Intensitas Nyeri Dismenore pada Remaja Putri di SMK YPIB Majalengka Kabupaten Majalengka Tahun 2019

\begin{tabular}{|c|c|c|c|c|c|c|}
\hline Variabel & Mean & $\mathbf{N}$ & $\begin{array}{c}\text { Beda } \\
\text { Mean }\end{array}$ & SD & $\mathbf{t}$ & $\rho$ value \\
\hline $\begin{array}{c}\text { Nyeri sebelum } \\
\text { senam } \\
\text { dismenore }\end{array}$ & 5.07 & 15 & \multirow{2}{*}{1,8} & 1.486 & \multirow{2}{*}{8,088} & \multirow{2}{*}{0,0001} \\
\hline $\begin{array}{c}\text { Nyeri sesudah } \\
\text { senam } \\
\text { dismenore }\end{array}$ & 3.27 & 15 & & 1.033 & & \\
\hline
\end{tabular}


Berdasarkan tabel 4 menunjukkan bahwa rata-rata intensitas nyeri dismenore pada kelompok eksperimen sebelum senam dismenore sebesar 5,07 dengan standar deviasi sebesar 1,468, sementara rata-rata intensitas nyeri sesudah senam dismenore sebesar 3,27 dengan standar deviasi sebesar 1,033. Hal ini menunjukkan bahwa terdapat penurunan intensitas nyeri sebelum dan sesudah senam dismenore sebesar 1,8 .

Hasil penghitungan statistik dengan paired sample t-test diperoleh tvalue $=8,088$ dan $\rho$ value $=0,0001$ yang berarti $\rho$ value $<\alpha(0,05)$, sehingga hipotesis nol ditolak. Dengan demikian maka senam dismenore efektifitas terhadap penurunan intensitas nyeri dismenore pada remaja putri di SMK YPIB Majalengka Kabupaten Majalengka Tahun 2019.

\section{Pembahasan}

a. Gambaran Intensitas Nyeri Sebelum dan Sesudah Senam Dismenore

Berdasarkan hasil penelitian menunjukkan bahwa sebelum senam dismenore lebih dari setengah $(66,7 \%)$ remaja putri pada kelompok eksperimen mengalami intensitas nyerinya sedang saat dismenore dan sesudah senam dismenore lebih dari setengah $(77,3 \%)$ remaja putri pada kelompok eksperimen mengalami intensitas nyerinya ringan saat dismenore. Sementara pada kelompok kontrol, lebih dari setengah $(80,0 \%)$ remaja putri mengalami intensitas nyerinya sedang saat dismenore pada saat pengukuran yang ke-1 dan lebih dari setengah $(73,3 \%)$ remaja putri mengalami intensitas nyerinya sedang saat dismenore pada saat pengukuran yang ke-2. Hal ini menunjukkan bahwa pada remaja puteri yang diberi perlakuan senam dismenore mengalami perubahan intensitas nyeri yang signifikan dibanding yang tidak diberi perlakuan. Pada remaja puteri yang diberi senam dismenore, banyak yang mengalami penurunan nyeri dari skala sedang menjadi ringan, sedangkan pada remaja puteri yang tidak diberi perlakuan cenderung tetap atau tidak ada perubahan.

Siswi yang mengalami intensitas nyeri saat dismenorepada penelitian dapat dikarenakan kurang informasi tentang penanganan nyeri secara non farmakologis seperti senam dismenore yang mudah dan tanpa biaya. Kurang mengetahui cara tersebut sehingga apabila siswi mengalami nyeri dismenore cenderung tidak dilakukan penanganan apa pun. Hal ini juga didukung kondisi mading (majalah dinding) di SMK YPIB Majalengka yang minim informasi berkaitan dengan kesehatan respoduksi remaja khususnya tentang pencegahan dan penanganan nyeri diosmenore.

Hasil penelitian ini tidak berbeda dengan hasil penelitian Sormin (2014) di SMP Negeri 2 Siantan Kabupaten Pontianak menurut hasil penelitiannya senam dismenore terbukti efektif dalam mengurangi dismenore dan dapat dijadikan sebagai salah satu intervensi keperawatan non-farmakologis dalam mengurangi dismenorea. Demikian juga hasil penelitian Marlinda (2013) pada remaja putri di Desa Sidoharjo Kecamatan Pati menunjukkan bahwa intensitas nyeri pada remaja puteri sebelum senam sebagian besar adalah nyeri sedang 
(65\%) dan sesudah senam sebagian besar menurun menjadi nyeri ringan $(70,0 \%)$.

Dismenore sering kali menyerang sebagian besar perempuan.Dismenore merupakan gejala, bukan penyakit.Gejalanya berupa nyeri dibagian perut bawah. Kasus-kasus tertentu, nyeri dapat dirasakan sampai seputar panggul dan sisi dalam paha. Nyeri terasa terutama pada hari pertama dan kedua menstruasi. Penyebabnya bermacam-macam dari meningkatnya prostaglandin sampai perubahan hormonal. Berdasarkan penyebabnya, nyeri menstruasi dibedakan menjadi dua, yaitu nyeri menstruasi primer dan sekunder (Oktasari, 2015).

Nyeri adalah pengalaman sensori dan emosional yang tidak menyenangkan akibat dari kerusakan jaringan yang aktual atau potensial.Skala nyeri dapat dibagi atas pasien yang memiliki kemampuan verbal dan dapat melaporkan sendiri rasa sakitnya (self reported) (Perry dan Potter, 2015). Dismenore biasanya terjadi pada saat fase pramenstruasi (sekresi). Pada fase ini terjadi peningkatan hormon prolaktin dan hormon estrogen.Sesuai dengan sifatnya, prolaktin dapat meningkatkan kontraksi uterus. Hormon yang juga terlibat dalam dismenore adalah hormon prostaglandin (Manuaba, 2015).

Dismenore biasanya terjadi akibat pelepasan berlebihan prostaglandin tertentu yaitu Prostaglandin-F2 alfa, dari sel sel endometrium uterus. Prostaglandin-F2 alfa adalah suatu perangsang kuat kontraksi otot polos miometrium dan konstriksi pembuluh darah uterus. Hal ini memperparah hipoksia uterus yang secara normal terjadi pada menstruasi, sehingga timbul rasa nyeri hebat (Manuaba, 2015).

Cara mengurangi dysmenorrhea dapat dilakukan dengan dua cara yaitu farmakologi dan non farmakologi. Kompres hangat atau mandi air hangat, latihan fisik, massase, hipnoterapi, tidur yang cukup, distraksi seperti mendengarkan musik serta relaksasi seperti yoga dan nafas dalam merupakan upaya non farmakologi (Muttaqin, 2015).

Senam dismenore merupakan salah satu bentuk relaksasi yang sangat dianjurkan. Tujuan dilakukannya senam dismenore adalah mengurangi dismenore yang dialami oleh beberapa wanita tiap bulannya (Suparto, 2015). Hal ini disebabkan saat melakukan olahraga atau senam, tubuh akan menghasilkan hormon endorphin. Endorphin dihasilkan oleh otak dan susunan saraf tulang belakang. Hormon ini berperan sebagai obat penenang alami yang diproduksi oleh otak sehingga menimbulkan rasa nyaman (Haruyama, 2014). Pada seorang atlet yang teratur berolahraga memiliki tingkat prevalensi kejadian dismenore lebih rendah dibandingkan dengan wanita yang mengalami obesitas, dan pada wanita yang memiliki siklus menstruasi yang tidak teratur (Laila, 2015).

Masih banyaknya remaja puteri yang mengalami intensitas nyeri saat menstruasi dengan skala ringan, sedang bahkan berat, maka bagi pihak sekolah sebaiknya bekerja sama dengan petugas kesehatan melakukan penyuluhan cara 
mengatasi dismenore denganyang mudah dan murah yaitu dengan senam dismenore dan bagi remaja yang mengalami dismenore jangan dibiarkan begitu saja harus segera dilakukan senam, juga perlu memanfaatkan mading di sekolah untuk mensosialisasikan tentang cara mengatasi dismenore selain dengan senam juga dapat dilakukan dengan cara lain yang juga praktis seperti kompres hangat. Perlunya komunikasi dengan guru atau orang tua, atau bisa berkonsultasi dengan petugas kesehatan jika mengalami keluhan yang tidak wajar saat dismenore, seperti nyeri sangat hebat dan kondisi tubuh melemas agar mendapatkan penanganan dengan tepat.

b. Efektivitas Senam Dismenore Terhadap Penurunan Intensitas Nyeri Dismenore

Berdasarkan hasil penelitian menunjukkan bahwasenam dismenore berpengaruh terhadap terhadap penurunan intensitas nyeri dismenore pada remaja putri di SMK YPIB Majalengka Kabupaten Majalengka Tahun 2019. Besarnya penurunan intensitas nyeri sebelum dan sesudah senam dismenore sebesar 1,8. Adanya pengaruh hal ini dikarenakan senam dismenore dapat mengurangi kekhawatiran yang timbul ketika menstruasi. Latihan-latihan olahraga yang ringan sangat dianjurkan untuk mengurangi dismenorea. Hal ini disebabkan karena saat melakukan olahraga/senam, otak dan susunan saraf tulang belakang akan menghasilkan endorphin, hormon yang berfungsi sebagai obat penenang alami dan menimbulkan rasa nyaman.

Sama halnya dengan penelitian (Rahayu, 2015) mengenai pada mahasiswa Program Studi D III Kebidanan Karawang menunjukakn bahwa ada perbedaan yang signifikan antara derajat dismenore sebelum senam dan sesudah senam. Juga hasil penelitian (Nuraeni, 2015) pada remaja putri SMK 1 Tapango Kabupaten Polewali Mandar menunjukan bahwa ada pengaruh diberikan dan tidak diberikan senam dismenore terhadap penurunan nyeri. Demikian juga dengan (Deharnita, 2014) tentang mengurangi nyeri dengan senam dismenore menunjukkan adanya perbedaan skala nyeri sebelum dan sesudah intervensi senam dismenore.

Hasil penelitian ini sejalan dengan teori bahwa senam dismenore merupakan salah satu bentuk relaksasi yang sangat dianjurkan. Tujuan dilakukannya senam dismenore adalah mengurangi dismenore yang dialami oleh beberapa wanita tiap bulannya (Suparto, 2015). Hal ini disebabkan saat melakukan olahraga atau senam, tubuh akan menghasilkan hormon endorphin. Endorphin dihasilkan oleh otak dan susunan saraf tulang belakang.Hormon ini berperan sebagai obat penenang alami yang diproduksi oleh otak sehingga menimbulkan rasa nyaman (Haruyama, 2014).

Senam dismenore merupakan salah satu teknik relaksasi yang dapat menghasilkan hormon $\beta$-endorphin, hormon ini diproduksi oleh otak dan susunan syaraf tulang belakang (Perry dan Potter, 2015). Senam dismenore adalah latihan-latihan olahraga yang ringan yang berguna untuk mengurangi dismenore (Laila, 2015). 
Tujuan dilakukan senam dismenore adalah untuk mengurangi derajat nyeri dismenore. Adapun manfaatnya antara lain dapat meningkatkan kebugaran, mengoptimalkan daya tangkap, meningkatkan mental dan relaksasi fisik, meningkatkan perkembangan kesadaran tubuh, mengurangi ketegangan otot (kram), mengurangi nyeri otot, dan mengurangi rasa sakit pada saat menstruasi (dismenore) (Laila, 2015).

Perlunya meningkatkan informasi dan bimbingan serta pengawasan baik oleh orang tua maupun guru-guru di sekolah mengenai dismenore, pemanfaatan media informasi di sekolah (mading) untuk menginformasikan tentang masalah remaja puteri khususnya mengenai dismenoredan penanganan dismenore dengan senam atau pun dengan cara lainnya seperti kompres hangat serta peningkatan peran Unit Kesehatan Sekolah (UKS) dalam menangani siswi yang mengalami nyeri dismenore. Bagi remaja puteri agar berkomunikasi dengan guru atau orang tua mengenai masalah nyeri menstruasi, agar aktif mengakses informasi dari media tentang carasenam dismenore dan berkonsultasi dengan petugas kesehatan jika mengalami keluhan.

\section{Kesimpulan}

Sebelum senam dismenore lebih dari setengah $(66,7 \%)$ remaja putrimengalami intensitas nyerinya sedang dan sesudah senam dismenore lebih dari setengah $(77,3 \%)$ remaja putrimengalami intensitas nyerinya ringan saat dismenore. Senam dismenore efektivitas terhadap penurunan intensitas nyeri dismenore pada remaja putri di SMK YPIB Majalengka Kabupaten Majalengka Tahun 2019. Besarnya penurunan intensitas nyeri sebelum dan sesudah senam dismenore sebesar 1,8 . 


\section{BIBLIOGRAFI}

Andriyani. (2016). Hubungan Antara Usia Menarche Dan Lama Menstruasi Dengan Kejadian Dismenore Primer Pada Remaja Putri. eprints.ums.ac.id.

Dahlan, A. (2017). Pengaruh Terapi Kompres Hangat Terhadap Nyeri Haid (Dismenorea) Pada Siswi Smk Perbankan Simpang Haru Padang. Journal Endurance, 2(1) February 2017.

Deharnita. (2014). Mengurangi Nyeri Dengan Senam Dismenore. Jurnal Parallela, 1(Nomor 1, Juni 2014).

Haruyama. (2014). The Female Body. Batam: Interaksara.

Laila, N. N. (2015). Kesehatan Reproduksi Remaja dan Wanita. Jakarta: Salemba Medika.

Manuaba, I. (2015). Ilmu kebidanan Penyakit Kandungan dan KB. Jakarta: EGC.

Marmi. (2014). Gizi Dalam Kesehatan Reproduksi. Yogyakarta : Pustaka Pelajar.

Muttaqin, A. (2015). Asuhan Keperawatan. Jakarta: Penerbit Salemba Medika.

Nuraeni. (2015). Pengaruh Senam Dismenore Terhadap Penurunan Nyeri Pada Remaja Putri SMK 1 Tapango Kecamatan Tapango Kabupaten Polewali Mandar. Jurnal Ilmiah Bidan, Vol II No.II No. 1, 2017.

Oktasari, dkk. (2015). Perbandingan Efektivitas Kompres Hangat Dan Kompres Dingin Terhadap Penurunan Dismenorea Pada Remaja Putri. Program Studi Ilmu Keperawatan Universitas Riau.

Perry dan Potter. (2015). Buku Ajar Fundamental Keperawatan : Konsep,. Proses,dan Praktik. Alih Bahasa : Renata. Komalasari, dkk. Jakarta: EGC.

Price, S. (2016). Patofisiologi: Konsep Klinis Proses-proses Penyakit. Jakarta: EGC.

Rahayu. (2015). Efektifitas Senam Dismenore Dalam Mengurangi Dismeneore Pada Mahasiswa Program Studi D III Kebidanan Karawang. Jurnal Prodi Kebidanan Unsika.

Savitri, R. (2015). Gambaran Skala Nyeri Haid pada Usia Remaja. Artikel Penelitian. Jurnal Prodi Kebidanan Unsika.

Sormin. (2014). Efektivitas Senam Dismenore Dalam Mengurangi Dismenore Pada Remaja Putri di SMP Negeri 2 Siantan Kabupaten Pontianak. Jurnal Program Studi Keperawatan Fakultas Kedokteran Universitas Tanjungpura. 
Ayu Idaningsih dan Fitri Oktarini

Subandi, E. (2017). Pengaruh Mobilisasi Dini Terhadap Tingkat Nyeri Pada Pasien Post Operasi Sectio Caesarea Di Ruang Melati RSUD Gunung Jati Kota Cirebon Tahun 2017. Syntax Literate; Jurnal Ilmiah Indonesia, 2(5), 58-74.

Suparto. (2015). Efektivitas Senam Dismenore Dalam Mengurangi Dismenore Pada Remaja Putri. Phederal Journal. 